Article

\title{
Study on Optimization of Tungsten Ore Flotation Wastewater Treatment by Response Surface Method (RSM)
}

\author{
Liping Zhang ${ }^{*}$, Xiaofei Jiao $\mathbb{D}$, Shengnian $W u(\mathbb{D}$, Xuejing Song $\mathbb{(}$ and Ruihan Yao $\mathbb{C}$ \\ School of Chemical \& Environmental Engineering, China University of Mining \& Technology-Beijing, \\ Beijing 100083, China; zqt1900302051g@student.cumtb.edu.cn (X.J.); bqt2000302034@student.cumtb.edu.cn (S.W.); \\ sxj19940225@163.com (X.S.); zqt2000302082@student.cumtb.edu.cn (R.Y.) \\ * Correspondence: 108707@cumtb.edu.cn
}

check for updates

Citation: Zhang, L.; Jiao, X.; Wu, S.; Song, X.; Yao, R. Study on Optimization of Tungsten Ore Flotation Wastewater Treatment by Response Surface Method (RSM). Minerals 2021, 11, 184. https:// doi.org/10.3390/min11020184

Academic Editor: Raj Mukhopadhyay

Received: 28 December 2020

Accepted: 5 February 2021

Published: 10 February 2021

Publisher's Note: MDPI stays neutral with regard to jurisdictional claims in published maps and institutional affiliations.

Copyright: (c) 2021 by the authors. Licensee MDPI, Basel, Switzerland. This article is an open access article distributed under the terms and conditions of the Creative Commons Attribution (CC BY) license (https:// creativecommons.org/licenses/by/ $4.0 /)$.
Abstract: A large amount of collectors, inhibitors and modifiers such as oleic acid, water glass and sodium carbonate are added to the flotation processing of tungsten ore, resulting in the difficulty of the suspended solids (SS) with the residual water glass settling down in the flotation wastewater. The removal efficiency of the suspended solids is low with commonly used reagents like polyaluminium chloride (PAC) and polyacrylamide (PAM). This paper innovatively applied calcium chloride $\left(\mathrm{CaCl}_{2}\right)$ to treat flotation wastewater and optimized the dosage of $\mathrm{CaCl}_{2}, \mathrm{PAM}$ and the $\mathrm{pH}$ value. The experimental results showed that when the dosage of $595 \mathrm{mg} / \mathrm{L} \mathrm{CaCl}_{2}$ was combined with $21 \mathrm{mg} / \mathrm{L}$ PAM at $\mathrm{pH} 12$, the turbidity removal ratio could reach 99.98\%, and the residual turbidity of the supernatant was $0.23 \mathrm{NTU}$. The effluent could fully meet the requirements for reuse in industrial, urban miscellaneous and scenic environment water consumption (turbidity $<5$ NTU). The quadratic equation model fitted with Design-Expert 8.0.6 software was constructed as $\mathrm{Y}=91.52+8.68 \mathrm{~A}+1.11 \mathrm{~B}-1.02 \mathrm{C}-1.7 \mathrm{AB}+0.86 \mathrm{AC}+0.06 \mathrm{BC}-1.56 \mathrm{~A}^{2}+2.09 \mathrm{~B}^{2}-1.89 \mathrm{C}^{2}$, which had a good accuracy of the predicted responses versus the experimental data.

Keywords: flotation wastewater; water glass; calcium chloride; cationic PAM; RSM

\section{Introduction}

Tungsten ore is one of the dominant minerals in China and plays an important role in the national economy. According to the data in China Mineral Resources 2019, by the end of 2018, tungsten resource reserves were 10,715,700 tons, which accounts for 58\% of the world's total tungsten reserves. The production of tungsten concentrate has reached 120,000 to $150,000 \mathrm{t} / \mathrm{a}$ in recent years [1]. According to the statistical data from the second national census of pollution sources, an average of 4.4 tons of flotation wastewater would be produced for 1 ton of raw tungsten ore in the flotation process. Due to the low utilization efficiency of reagents in the flotation process, large amounts of residual reagents remained in the flotation wastewater which were certainly toxic to the ecological environment. The main pollutants of flotation wastewater include suspended solids (SS), heavy metal ions and residual flotation reagents [2,3]. The most commonly used reagents for the tungsten ore flotation process include collectors such as oleic acid, sodium oleate and hydroxamate, inhibitors like sodium silicate and regulators such as sodium carbonate $[4,5]$. The discharge of flotation wastewater containing residual flotation reagents could result in serious water pollution and ecological environment damage. With the continuous improvement of China's ecological environment requirements, efficient treatment and reuse of mineral flotation wastewater is an urgent problem for the mining industry [1].

At present, the research priority of flotation wastewater mainly focuses on degradation of organic matter and removal of heavy metal ions [6,7]. In the actual production process, most of the mineral flotation wastewater is reused in the mineral flotation processing after simple treatment. High-efficient removal of SS from the flotation wastewater is the key to improving the wastewater/reuse ratio. The SS in tungsten ore flotation wastewater are 
fine particles; meanwhile, a large number of sodium silicate as inhibitor is added during the flotation process, which makes the flotation wastewater viscous and is mixed with the fine particles to form colloids with a negative charge, making it difficult for the SS to settle down [8]. To remove the SS from tungsten flotation wastewater, the most commonly used treatment method is adding acid, alkali or strong electrolytes to eliminate colloid stability; flocculants such as PAC, PAM and other composite flocculants are then added to accelerate the formation of coarse particle polymers to improve the settlement [8-11]. The problems of these methods are their large dosages, high costs and slow clarification speeds. The reuse of mineral processing wastewater after treatment has adverse effects on the grade and recovery of tungsten concentrates $[12,13]$. It is urgent to find a cheaper and more efficient coagulant and optimize experimental parameters for the treatment and reuse of mineral processing wastewater.

The response surface model (RSM) is a statistical technique proposed by Box and Wilson, which can be used for process parameter modeling and optimization [14]. It is widely used in wastewater treatment, especially in improving the efficiency of pollutant removal. Xie Yawei [15] used the RSM to study the removal effect of adsorbed organic halogen and total organic carbon in pharmaceutical wastewater treated by the Fenton method. Yang Yu [16] applied hybrid coagulants and PAM flocculants to the treatment of high-phosphorus hematite flotation wastewater optimized through response surface methodology. A minimum residual turbidity of 0.8 NTU was achieved when the dosage of coagulant B4 and PAM-N was $356 \mathrm{mg} / \mathrm{L}$ and $5.4 \mathrm{mg} / \mathrm{L}$, respectively. The concentration of iron, aluminum and COD in the purified high-phosphorus hematite flotation was $0.055 \mathrm{mg} / \mathrm{L}, 0.184 \mathrm{mg} / \mathrm{L}$ and $33.92 \mathrm{mg} / \mathrm{L}$, respectively. Dawood [17] used the RSM to synthesize a novel hybrid polymer and optimize the amount of hybrid polymer, initial $\mathrm{pH}$ and other experimental factors on flocculation.

This paper studied a novel coagulate agent and used the RSM to optimize the dosage to achieve the highest removal ratio of the SS in flotation wastewater, thus reducing the cost, improving the treatment efficiency of tungsten flotation wastewater and realizing the comprehensive utilization of water resources.

\section{Materials and Methods}

\subsection{Experimental Water}

Scheelite is often associated with fluorite and calcite in nature. Due to their similar surface chemical composition, the difficulty of scheelite flotation is the separation of scheelite from Ca-containing minerals. Thus, $\mathrm{NaCO}_{3}$ ( $\mathrm{pH}$ regulator) and $\mathrm{Na}_{2} \mathrm{SiO}_{3}$ (inhibitor) must be added before flotation to improve selectivity. According to references and the monitoring data of mineral processing wastewater from a large tungsten mine in Jiangxi Province, anionic collectors of fatty acids such as oleic acid and sodium oleate are commonly used for the scheelite flotation process [18,19], and the $\mathrm{pH}$ value, COD, SS and No. 2 oil of the flotation wastewater was $8.0,159 \mathrm{mg} / \mathrm{L}, 2187 \mathrm{mg} / \mathrm{L}$ and $11.8 \mathrm{mg} / \mathrm{L}$, respectively.

The experimental water was prepared as follows: $500 \mathrm{mg} \mathrm{NaCO}, 2500 \mathrm{mg} \mathrm{Na}_{2} \mathrm{SiO}_{3}$, $3000 \mathrm{mg}$ powdered tungsten ore and $225 \mu \mathrm{L}$ oleic acid were added to $1 \mathrm{~L}$ of deionized water and stirred in a constant temperature magnetic stirrer with $500 \mathrm{r} / \mathrm{min}$ for $15 \mathrm{~min}$. The $\mathrm{pH}$ value, turbidity, SS and zeta potential was $12.26,1390 \mathrm{NTU}, 2780 \mathrm{mg} / \mathrm{L}$ and $-59.9 \mathrm{mV}$, respectively. The particle size distribution is shown in Figure 1, and the gravity settlement effect is shown in Figure 2. 


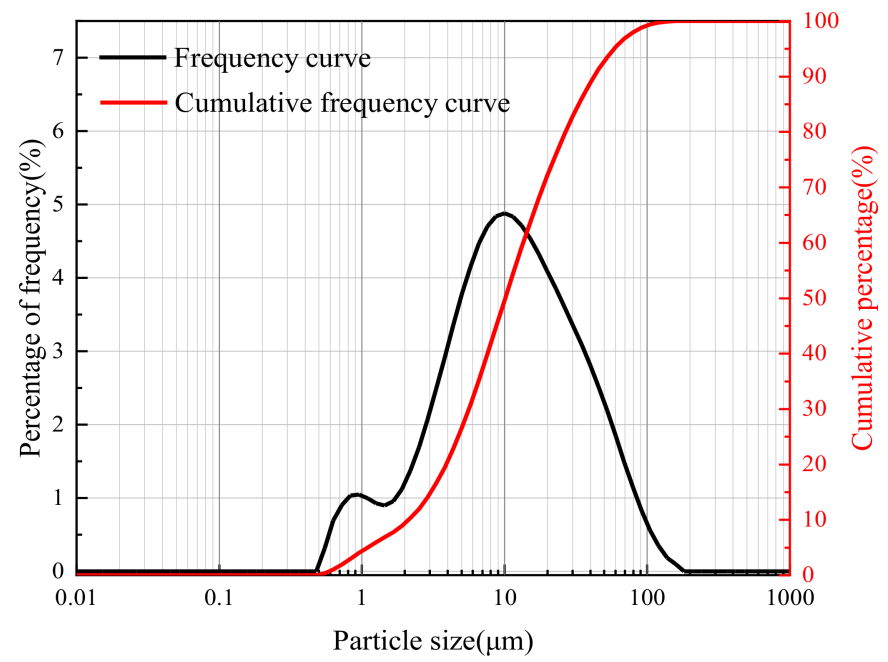

Figure 1. Particle size distribution of tungsten ore flotation wastewater.

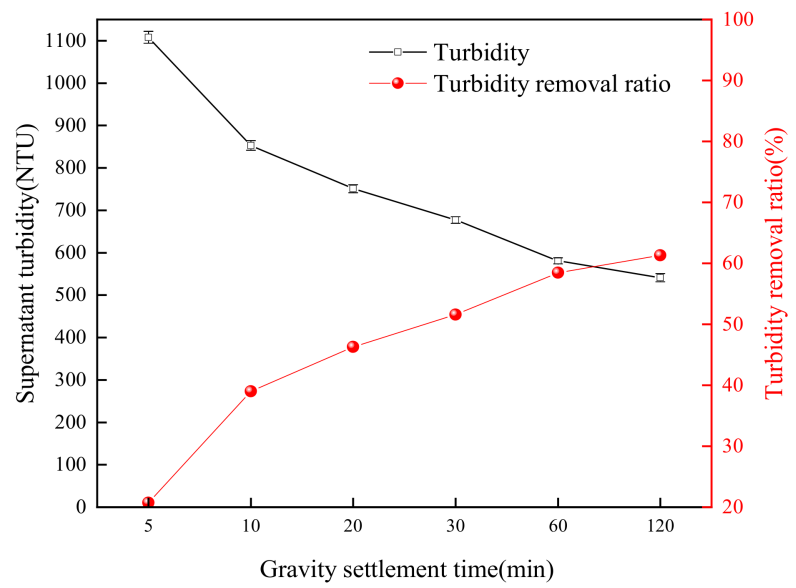

Figure 2. Gravity sedimentation effect of prepared flotation wastewater.

Figure 1 shows that about $50 \%$ of the particles in the prepared flotation wastewater were smaller than $10 \mu \mathrm{m}$, and more than $90 \%$ of the total particles in the flotation wastewater were smaller than $42 \mu \mathrm{m}$. It could be inferred that the particle size of the prepared flotation wastewater was very fine.

Figure 2 illustrates that the fine particles were difficult to settle down by gravity. The turbidity removal ratio of flotation wastewater gradually increased to $51.6 \%$ after $30 \mathrm{~min}$ of gravity settlement, and the turbidity of the supernatant was decreased to 677 NTU. With the gravity settlement time prolonged to $120 \mathrm{~min}$, the turbidity of the supernatant was 541 NTU and the turbidity removal ratio was increased to $61.3 \%$. The water quality of the effluent did not meet the wastewater discharge standard or the requirements of reuse standard.

\subsection{Experimental Methods}

Different coagulants or coagulant aids with different dosages were added into the $1 \mathrm{~L}$ of prepared flotation wastewater, stirred with $450 \mathrm{r} / \mathrm{min}$ for $2 \mathrm{~min}$, which was then slowed to $160 \mathrm{r} / \mathrm{min}$ for $5 \mathrm{~min}$ and settled down for $30 \mathrm{~min}$. The supernatant was taken to measure the turbidity and calculate the removal ratio. The optimal coagulant or coagulant aid and dosage could be screened out.

According to the basic rules of RSM and the central composite design (CCD) method, the main factors affecting coagulation effect were chosen as the main independent variables in the RSM designing, and the supernatant turbidity removal ratio of flotation wastewater 
was selected as the response parameter. Based on the above experimental results, the different levels of the independent variables were determined, then the vertex experiments, the axial point experiments and the central point experiments of the multidimensional cube were designed. All the experiments were carried out with the same optimal stirring speed and stirring time, and the settlement time was $30 \mathrm{~min}$; the supernatant was then sampled to analyze the turbidity, and the turbidity removal ratio was calculated.

\subsection{Chemicals and Analyses}

Analytical grade $\mathrm{NaCO}_{3}, \mathrm{NaSiO}_{3}$, oleic acid, $\mathrm{H}_{2} \mathrm{SO}_{4}, \mathrm{NaOH}, \mathrm{CaCl}_{2}$ and $\mathrm{CaO}$ were purchased from Sinopharm (Beijing, China). Analytical grade PAC, PAM, polyferric sulfate (PFS) and aluminum potassium sulfate $\left(\mathrm{KAl}\left(\mathrm{SO}_{4}\right)_{2}\right)$ were purchased from Macklin Biochemical Co. (Shanghai, China). Scheelite samples were collected from a large tungsten mine in Jiangxi Province.

The $\mathrm{pH}$ value was measured by $\mathrm{pH}$ meter (PHS-3C, Raytheon, China), turbidity was analyzed by turbidimeter (WZS-186, Raytheon, China), particle size was tested by laser particle sizer (Mastersizer 2000, Malvern Panalytical, Malvern, UK) and zeta potential was measured by zeta potentiometer (ZS90, Malvern Panalytical, Malvern, UK).

In order to simplify the subsequent determination of SS concentration, the corresponding relationship between SS concentration and turbidity of the prepared flotation wastewater are shown in Figure 3.

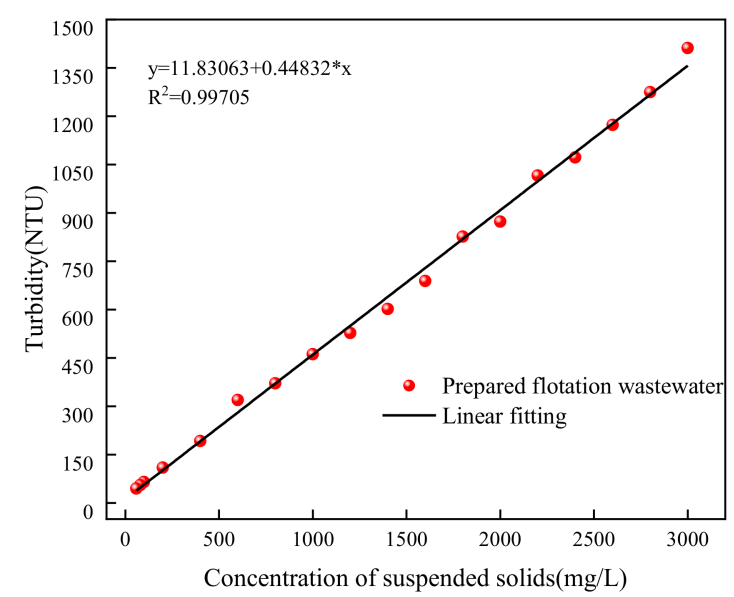

Figure 3. Relationship between SS concentration and turbidity of the prepared flotation wastewater.

\section{Results and Discussion}

\subsection{Optimization of Coagulant}

Aimed at solving the existing problems such as difficult sedimentation of tungsten flotation wastewater, large dosages of traditional coagulants and high treatment costs, PAC, PFS, $\mathrm{KAl}\left(\mathrm{SO}_{4}\right)_{2}$, lime and $\mathrm{CaCl}_{2}$ were selected as coagulants to treat the prepared flotation wastewater. The dosage of each coagulant was $500 \mathrm{mg} / \mathrm{L}$. The results of the turbidity removal ratio are shown in Figure 4 and the zeta potentials of the treated flotation wastewater are shown in Figure 5.

Figure 4 showed that the turbidity removal ratio of the prepared flotation wastewater with PAC, PFS, $\mathrm{KAl}\left(\mathrm{SO}_{4}\right)_{2}, \mathrm{CaO}$ and $\mathrm{CaCl}_{2}$ was $60.6 \%, 58.8 \%, 72.5 \%, 62.0 \%$ and $96.3 \%$, respectively. The efficiency of $\mathrm{CaCl}_{2}$ was significantly higher than that of other coagulants; the supernatant turbidity was only 49.8 NTU and the SS was decreased to $67.2 \mathrm{mg} / \mathrm{L}$. The price per ton of PAC, PFS, $\mathrm{KAl}\left(\mathrm{SO}_{4}\right)_{2}, \mathrm{CaO}$ and $\mathrm{CaCl}_{2}$ is $2000-2500 \mathrm{RMB}, 1500-2000 \mathrm{RMB}$, 1700-2000 RMB and 1000-1500 RMB, respectively, which highlights the lower treatment cost of $\mathrm{CaCl}_{2}$. 


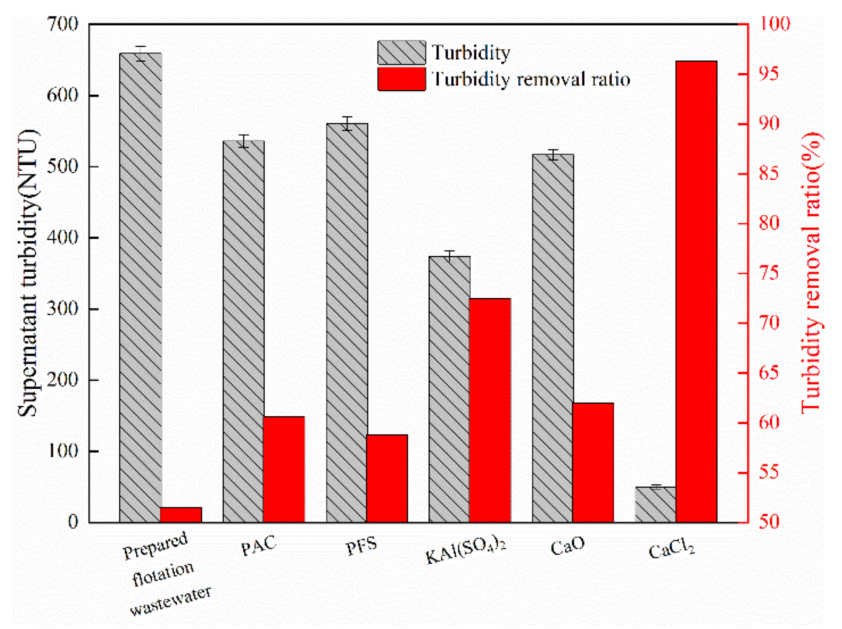

Figure 4. Treatment effect of different coagulants on the prepared flotation wastewater.

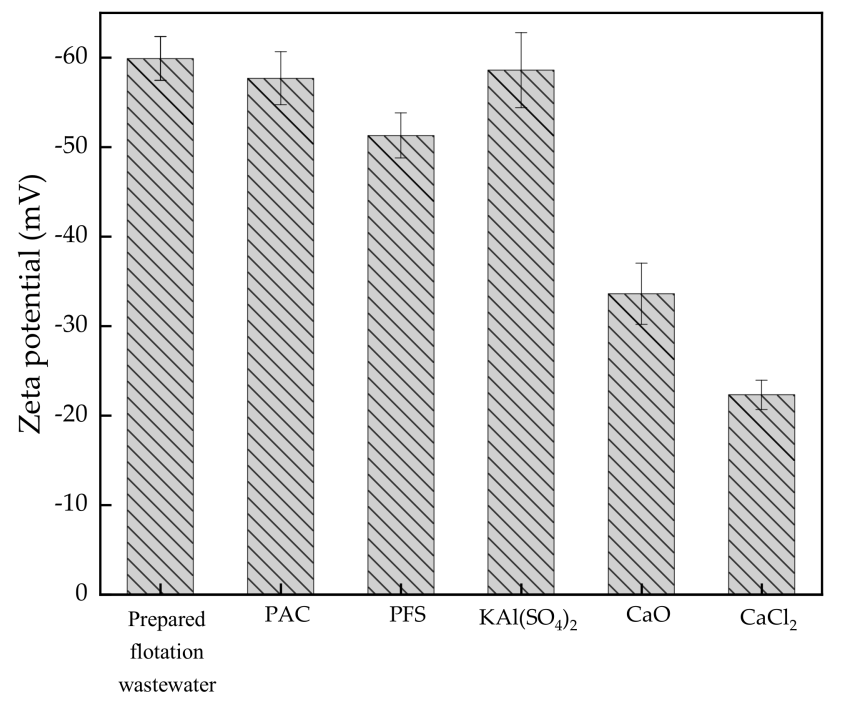

Figure 5. Zeta potential of prepared flotation wastewater treated by different coagulants.

The zeta potential of prepared flotation wastewater was $-59.9 \mathrm{mV}$, which reached colloidal property causing difficult settlement. With the same $500 \mathrm{mg} / \mathrm{L}$ dosage of PAC, PFS, $\mathrm{KAl}\left(\mathrm{SO}_{4}\right)_{2}$, lime and $\mathrm{CaCl}_{2}$, the zeta potential of the supernatant was $-57.5 \mathrm{mV},-51.3 \mathrm{mV}$, $-58.6 \mathrm{mV},-33.6 \mathrm{mV}$ and $-22.3 \mathrm{mV}$, respectively. The change of zeta potential was basically consistent with the change of turbidity removal ratio. The more the absolute value of zeta potential was decreased, the more obvious the turbidity removal effect became. When the dosage of $\mathrm{CaCl}_{2}$ was $500 \mathrm{mg} / \mathrm{L}$, the zeta potential of the supernatant was the lowest, and the turbidity removal ratio was at the maximum of $96.3 \% . \mathrm{CaCl}_{2}$ was easily soluble, and a large number of $\mathrm{Ca}^{2+}$ ions was produced, which could destroy the stability of the colloid and reduce the zeta potential with electric neutralization and compression of the electric double-layer mechanism [20,21]. Meanwhile, $\mathrm{Ca}^{2+}$ reacted with $\mathrm{SiO}_{3}{ }^{2-}$ to form $\mathrm{CaSiO}_{3}$ precipitation. $\mathrm{Ca}^{2+}$ could also activate silica on the surface of tungsten particles to form calcium complexes, which could produce large flocs by the adsorption-bridging process. $\mathrm{Ca}^{2+}$ could also react with hydrogen peroxide to form monohydroxy complex $\mathrm{Ca}(\mathrm{OH})^{+}$, which could adsorb the silicon hydroxyl group on the surface of tungsten particles and decrease the zeta potential. $\mathrm{CaO}$ dissolved in water to form $\mathrm{Ca}(\mathrm{OH})_{2}$, which reacted with $\mathrm{SiO}_{2}$ on the surface of tungsten particles to form a hard calcium silicate layer. $\mathrm{Ca}(\mathrm{OH})_{2}$ was slightly soluble in water and could not provide enough $\mathrm{Ca}^{2+}$ to participate in the reaction like $\mathrm{CaCl}_{2}$. Thus, the removal efficiency of $\mathrm{CaO}$ was much lower than that of $\mathrm{CaCl}_{2}$. 


\subsection{Design Results and Analysis of Central Combination Experiment}

According to the previous research results of our research group [1], RSM was applied to optimize the three most important independent variables: $\mathrm{CaCl}_{2}$ dosage, PAM dosage and $\mathrm{pH}$ value. The values for $\mathrm{CaCl}_{2}$ dosage, $\mathrm{PAM}$ dosage and $\mathrm{pH}$ were set at three levels: -1 (minimum), 0 (central) and +1 (maximum). The ranges of the three variables were presented in Table 1.

Table 1. Range and level of the independent variables.

\begin{tabular}{ccccc}
\hline \multirow{2}{*}{ Symbol } & Independent Variables & \multicolumn{3}{c}{ Range and Level } \\
\cline { 3 - 5 } & & $\mathbf{- 1}$ & $\mathbf{0}$ & $\mathbf{+ 1}$ \\
\hline $\mathrm{A}$ & $\mathrm{CaCl}_{2}$ dosage $(\mathrm{mg} / \mathrm{L})$ & 200 & 400 & 600 \\
$\mathrm{~B}$ & $\mathrm{PAM}$ dosage $(\mathrm{mg} / \mathrm{L})$ & 20 & 30 & 40 \\
$\mathrm{C}$ & $\mathrm{pH}$ value & 11 & 12 & 13 \\
\hline
\end{tabular}

The CCD method was employed to design the experiments, in which the design consisted of 20 runs including 8 apical points, 6 center points and 6 axial points. All test points were completed under the conditions of $450 \mathrm{r} / \mathrm{min}$ fast stirring for $2 \mathrm{~min}, 160 \mathrm{r} / \mathrm{min}$ slow stirring for $5 \mathrm{~min}$ and settling down for $30 \mathrm{~min}$. The turbidity of the supernatant was measured and the removal ratio was calculated.

The quadratic equation model in Design-Expert 8.0.6 was employed to carry out the statistical design of experiments and data analysis. The specific experimental design and results are presented in Table 2.

Table 2. Experiment and results designed by CCD.

\begin{tabular}{ccccc}
\hline Run & A & B & C & Y (Turbidity Removal Ratio) (\%) \\
\hline 1 & 600 & 40 & 13 & 99.52 \\
2 & 400 & 30 & 12 & 90.13 \\
3 & 400 & 30 & 13.68 & 83.96 \\
4 & 400 & 30 & 10.32 & 87.68 \\
5 & 600 & 20 & 13 & 99.58 \\
6 & 400 & 30 & 12 & 92.31 \\
7 & 400 & 13.18 & 12 & 96.51 \\
8 & 200 & 20 & 11 & 79.71 \\
9 & 200 & 20 & 13 & 75.83 \\
10 & 736.36 & 30 & 12 & 99.99 \\
11 & 600 & 40 & 11 & 99.71 \\
12 & 400 & 30 & 12 & 91.37 \\
13 & 63.64 & 30 & 12 & 73.53 \\
14 & 600 & 20 & 11 & 99.79 \\
15 & 200 & 40 & 11 & 86.17 \\
16 & 400 & 46.82 & 12 & 97.64 \\
17 & 400 & 30 & 12 & 91.42 \\
18 & 400 & 30 & 12 & 91.27 \\
19 & 400 & 30 & 12 & 92.71 \\
20 & 200 & 40 & 13 & 82.80 \\
\hline
\end{tabular}

According to the experimental results in Table 2, the quadratic equation model fitted with Design-Expert 8.0.6 software was constructed as follows:

$\mathrm{Y}=91.52+8.68 \mathrm{~A}+1.11 \mathrm{~B}-1.02 \mathrm{C}-1.7 \mathrm{AB}+0.86 \mathrm{AC}+0.06 \mathrm{BC}-1.56 \mathrm{~A}^{2}+2.09 \mathrm{~B}^{2}-1.89 \mathrm{C}^{2}$

This model could predict the relationship between the independent variables and the response variable $(\mathrm{Y})$. The model was also analyzed with the Fisher's statistical test for the analysis of variance (ANOVA) to obtain the interaction between the variables and the responses and to assess the quality of "goodness of fit". The quality of the fit polynomial model was expressed by the determination coefficient $R^{2}$ and adjusted $R^{2}$, and statistical 
significance was checked by the Fisher's F-test in the same program. Model terms were selected or rejected based on the $P$ value (probability) with a 95\% confidence level.

The variance analysis and reliability analysis of Equation (1) are shown in Tables 3 and 4.

Table 3. Variance analysis of the quadratic equation model.

\begin{tabular}{|c|c|c|c|c|c|}
\hline Source of Variance & Sum of Square & $\begin{array}{c}\text { Degree of } \\
\text { Freedom (df) }\end{array}$ & Mean Square & F Value & $P$ Value \\
\hline Model & 1253.23 & 9 & 139.25 & 79.12 & $<0.0001$ (significant) \\
\hline A & 1029.79 & 1 & 1029.79 & 585.1 & $<0.0001$ \\
\hline $\mathrm{B}$ & 16.9 & 1 & 16.9 & 9.6 & 0.0113 \\
\hline $\mathrm{C}$ & 14.16 & 1 & 14.16 & 8.05 & 0.0177 \\
\hline $\mathrm{AB}$ & 23.02 & 1 & 23.02 & 13.08 & 0.0047 \\
\hline $\mathrm{AC}$ & 5.87 & 1 & 5.87 & 3.33 & 0.0979 \\
\hline $\mathrm{BC}$ & 0.035 & 1 & 0.035 & 0.02 & 0.8905 \\
\hline $\mathrm{A}^{2}$ & 35.11 & 1 & 35.11 & 19.95 & 0.0012 \\
\hline $\mathrm{B}^{2}$ & 62.72 & 1 & 62.72 & 35.63 & 0.0001 \\
\hline$C^{2}$ & 51.65 & 1 & 51.65 & 29.35 & 0.0003 \\
\hline Residual & 17.6 & 10 & 1.76 & & \\
\hline Lack-of-fit test & 13.53 & 5 & 2.71 & 3.33 & 0.1065 (insignificant) \\
\hline Error & 4.07 & 5 & 0.81 & & \\
\hline Total dispersion & 1270.83 & 19 & & & \\
\hline
\end{tabular}

Table 4. Reliability analysis of the quadratic equation model.

\begin{tabular}{cc}
\hline Parameter & Value \\
\hline Correlation coefficient $\left(\mathrm{R}^{2}\right)$ & 0.9862 \\
Adjusted correlation coefficient $\left(\mathrm{R}_{\mathrm{adj}}{ }^{2}\right)$ & 0.9737 \\
Prediction correlation coefficient & 0.9145 \\
Signal-to-noise ratio & 31.14 \\
Standard deviation & 1.33 \\
Coefficient variation $(\mathrm{CV})(\%)$ & 1.46 \\
\hline
\end{tabular}

The influence of each independent variable on the turbidity removal ratio depended on the absolute value of the coefficient. The test of significance (F value) of the quadratic equation model was 79.12 and the $P$ value was lower than 0.0001 , which implied that the difference of the quadratic equation model was highly significant [22]. According to fit statistics, the correlation coefficient $\left(\mathrm{R}^{2}\right)$ was 0.9862 , which indicated a satisfactory fitting of the quadratic equation model to experimental data. Additionally, the value of the adjusted $R^{2}$ was 0.9737 , which could also confirm the accuracy of the quadratic equation model, and it could be used to explain the reason for the change of the turbidity removal ratio. The lack-of-fit test could describe the degree of difference between the quadratic equation model and the actual experiment. In this study, the $\mathrm{F}$ value and the $P$ value for lack-of-fit was 3.33 and $0.1065(>0.05)$, respectively, which showed that the lack-of-fit test was insignificantly relative to the pure error, implying a significant model correlation between the process variables and responses [23]. It also showed that the influence of unknown factors on the experimental results could be ignored.

Adequate precision (AP) compares the range of the predicted values at the design points to the average prediction error. In this study, the AP value was 31.14, which was much greater than 4 , indicating that the quadratic equation model could be used to navigate the design space defined by the CCD and accurately predict the experimental results. A model can be considered to be reproducible, if its $\mathrm{CV}$, the ratio of the standard error of predicted value to the mean value of the observed response, is not greater than $10 \%$ [23]. In this study, the $\mathrm{CV}$ value for the response was $1.46 \%$, suggesting good precision and reliability of the quadratic model.

The ANOVA of Table 3 indicated that variable A was the most significant parameter, implied by the high $\mathrm{F}$ value $(585.1)$ and low $P$ value $(<0.0001)$. Figure $6 \mathrm{~A}$ illustrates the 
significant influence of calcium chloride dosage on turbidity removal. Figure $6 \mathrm{~B}$ shows the actual values were distributed quite close to the diagnostic plot line, which indicated an adequate accuracy of the predicted responses versus the actual experimental data.
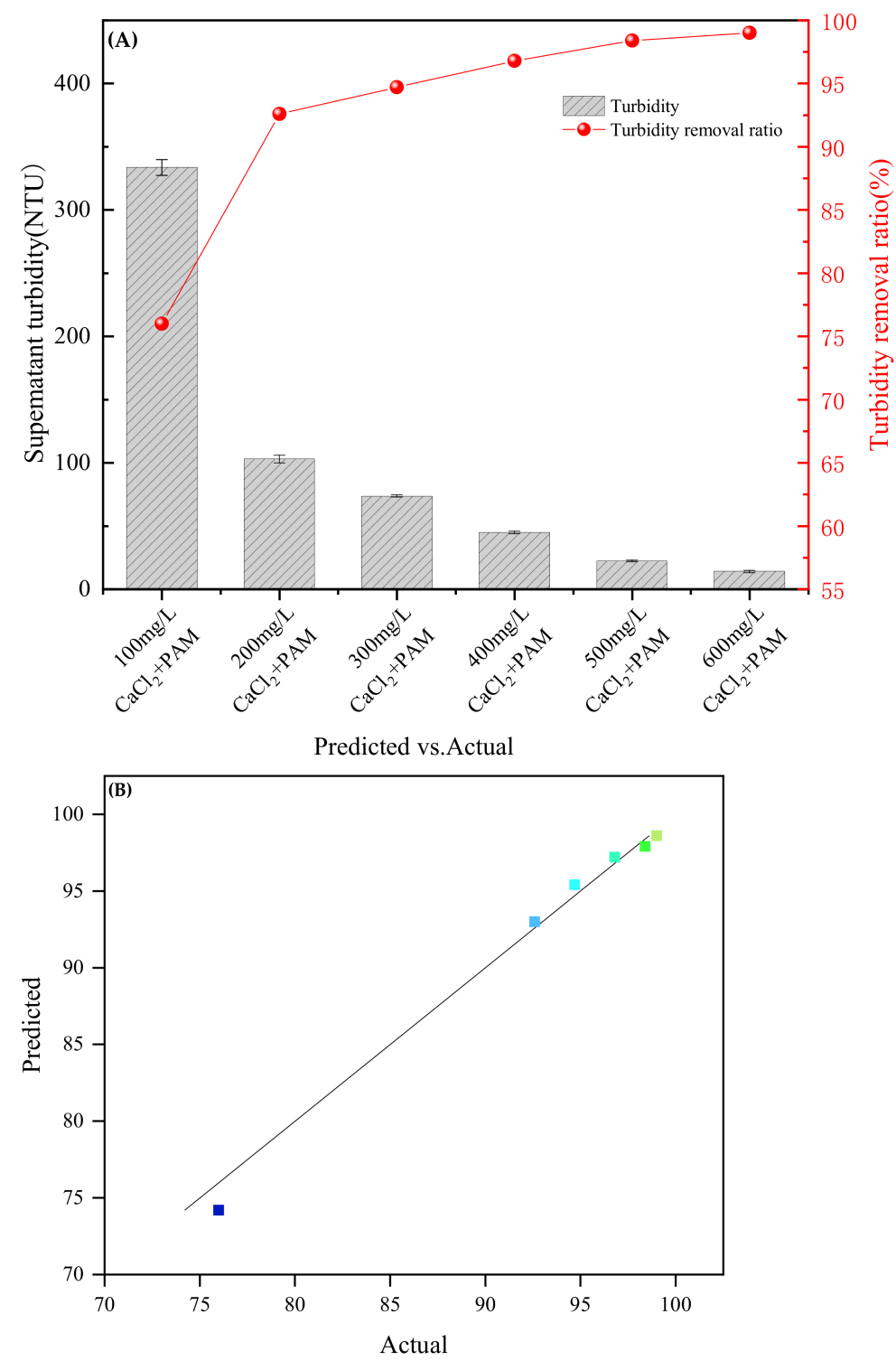

Figure 6. (A) Influence of $\mathrm{CaCl}_{2}$ dosage on turbidity removal. (B) Predicted vs. actual values plot for the turbidity removal ratio.

Based on the Design-Expert 8.0.6 software, the residuals and the closeness between the predicted values and the actual experimental values were expressed. Figure 7 shows the normal probability distribution of residuals. The correspondence between experimental serial numbers and residuals of experimental results is listed in Figure 8. The relationship between actual experimental results and predicted values of turbidity removal ratio is illustrated in Figure 9. 


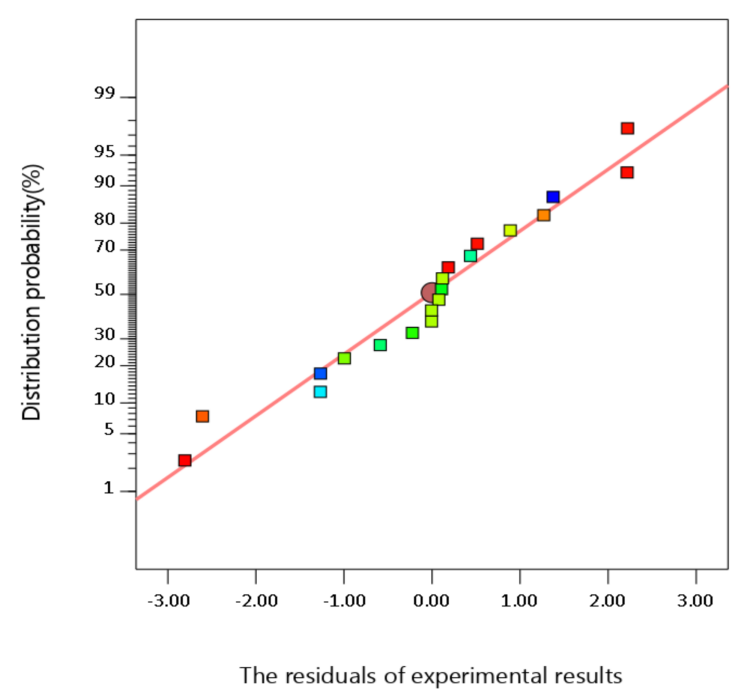

Figure 7. Normal probability distribution of residuals.

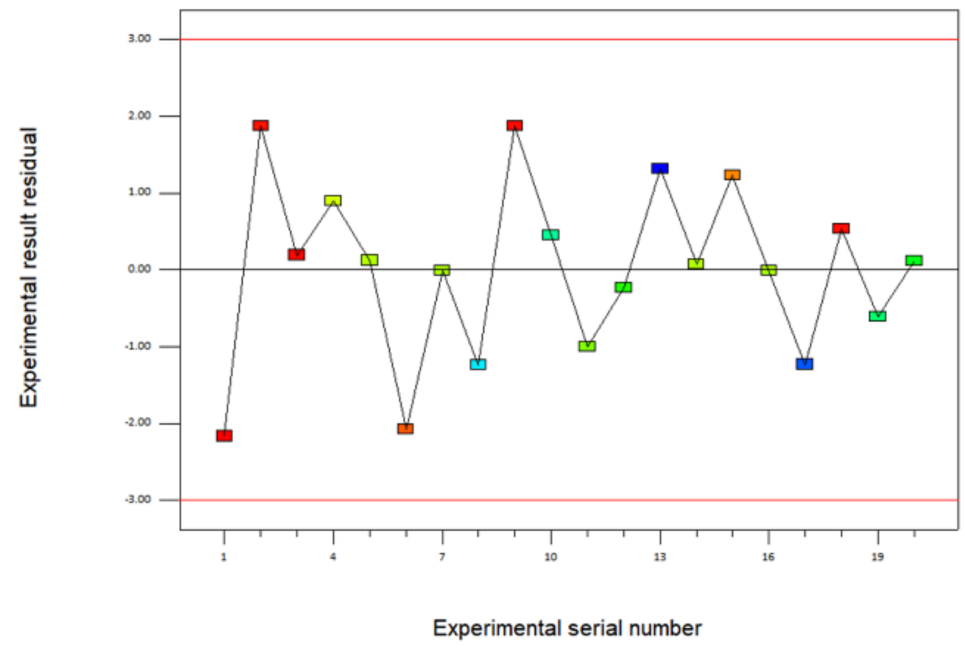

Figure 8. Correspondence between experimental serial number and experimental result residual.

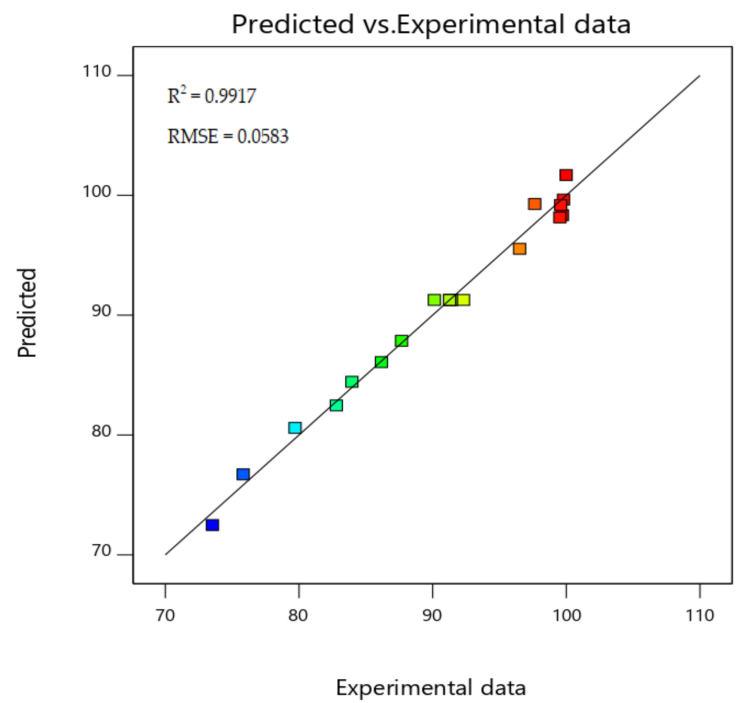

Figure 9. Predicted values vs. experimental results plot for the turbidity removal ratio. 
The residuals of the experimental results were basically in a straight line or evenly arranged on both sides. It could be found that the experimental results were of normal probability distribution, and $60 \%$ of the absolute residual values were less than 1 , which indicated that the residuals of experimental results were generally small and the deviation between the predicted values and the experimental results was also small. Thus, the quadratic response surface model was of good fitness.

Figure 8 illustrates that the residual of each experimental result was totally distributed in the range of \pm 2 , which meant the quadratic response surface model obtained through RSM had a high accuracy.

Figure 9 explains that the experimental results of the turbidity removal ratio were basically in a straight line or evenly arranged on both sides, the correlation coefficient $\left(R^{2}\right)$ was 0.9917 and the root mean square error (RMSE) was 0.0583 , which indicated that there was a high degree of confidence between the experimental results and the predicted values.

\subsection{Response Surface Analysis}

In order to deeply explore the interactive effect of related variables and provide visual analysis, the three-dimensional space map and projected two-dimensional contour map composed of different factors and response values were obtained through Design-Expert 8.0.6 software analysis. Through response surface, the curve bending degree and surface inclination could be directly observed, which could reflect the influence degree and the interaction of different factors on the experiment.

It could be seen from the variance analysis and significance test of the quadratic response surface model in Table $3, A, A B, A^{2}, B^{2}$ and $C^{2}$ had very significant effects on the turbidity removal ratio $(P<0.01)$. B and $C$ had a significant effect on the turbidity removal ratio $(P<0.05)$, but $\mathrm{AC}$ and $\mathrm{BC}$ had no significant effect on the turbidity removal ratio $(P>0.05)$. The response surfaces and contour maps of the turbidity removal ratio interacted by various factors are shown in Figures 10-12.
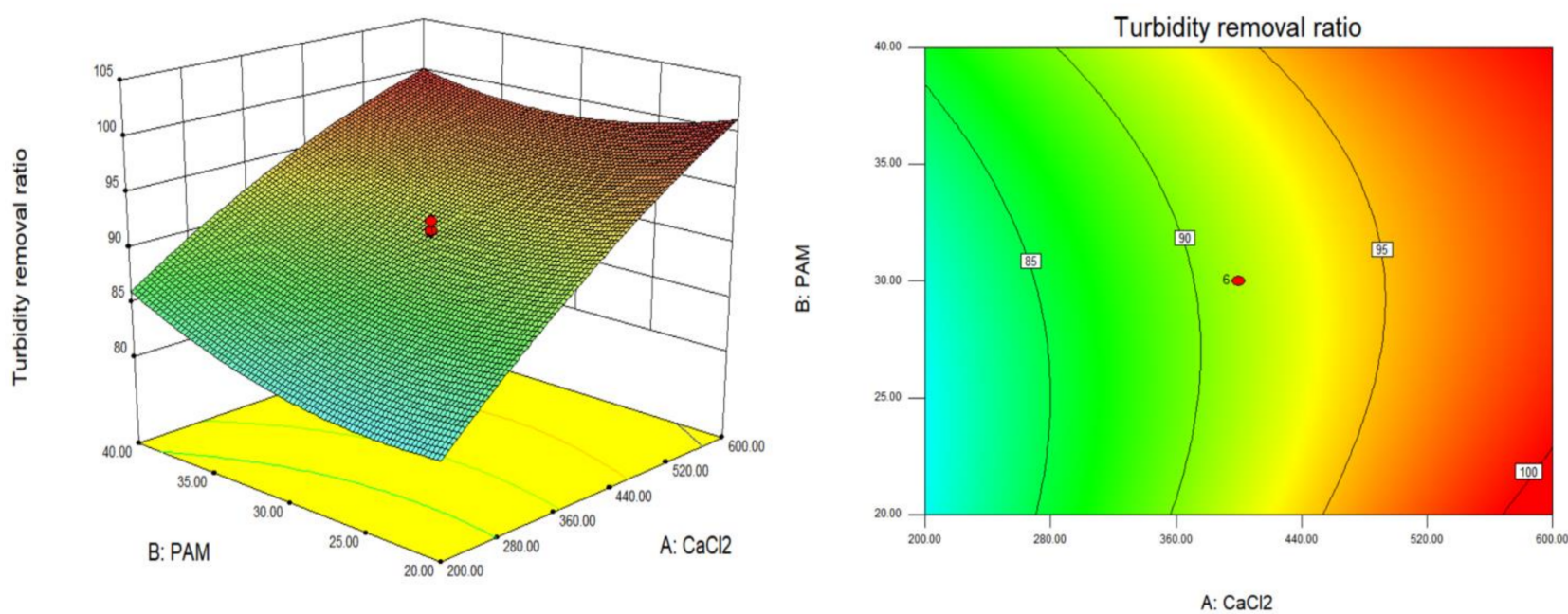

Figure 10. (left) Response surface of the turbidity removal ratio interacted by $\mathrm{CaCl}_{2}$ dosage and PAM dosage. (right) Contour map of the turbidity removal ratio interacted by $\mathrm{CaCl}_{2}$ dosage and PAM dosage. 

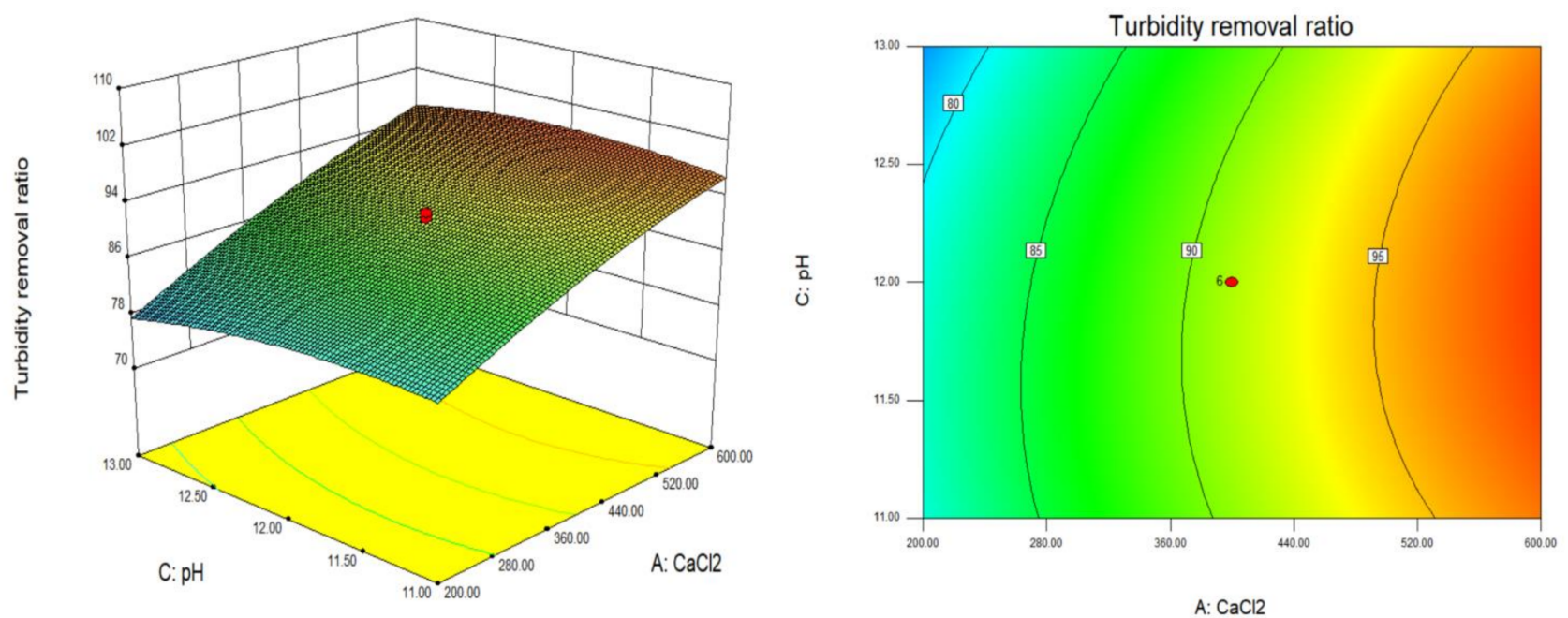

Figure 11. (left) Response surface of the turbidity removal ratio interacted by $\mathrm{CaCl}_{2}$ dosage and $\mathrm{pH}$ value. (right) Contour map of the turbidity removal ratio interacted by $\mathrm{CaCl}_{2}$ dosage and $\mathrm{pH}$ value.
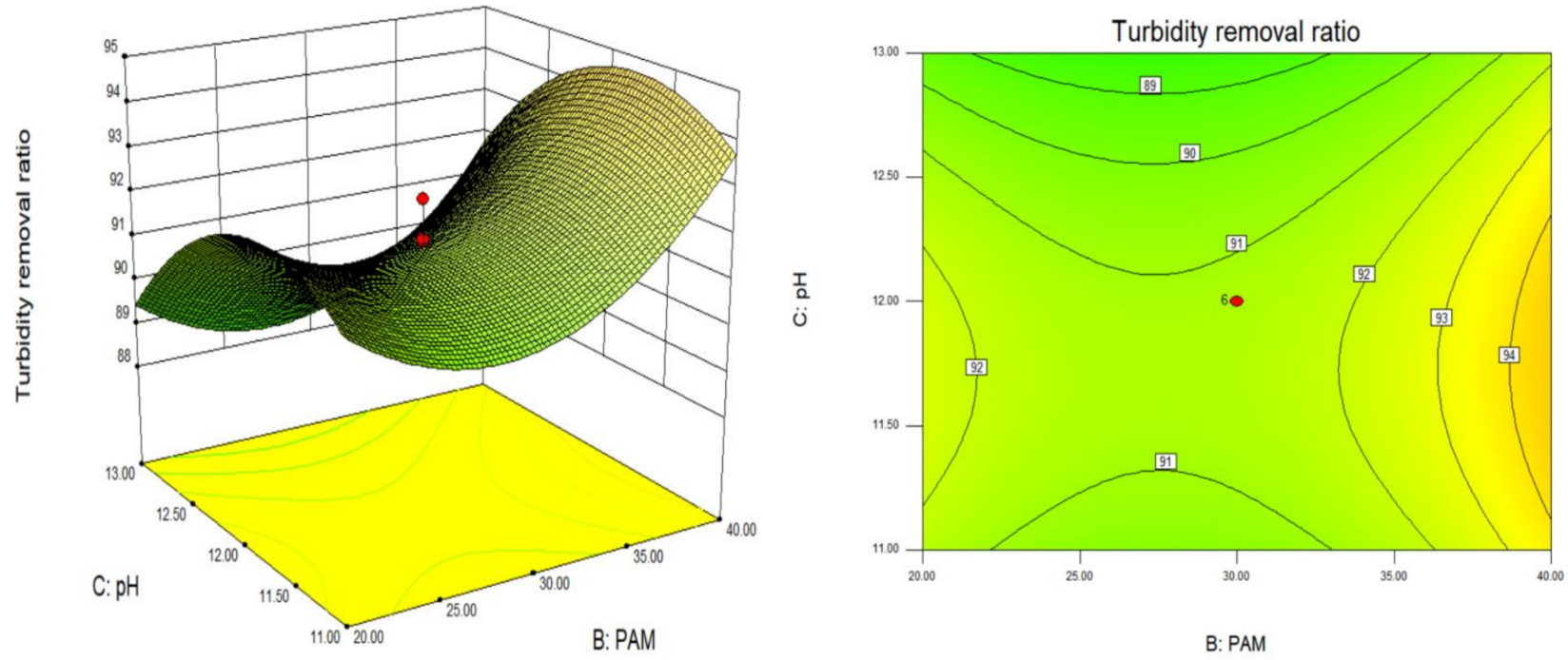

Figure 12. (left) Response surface of the turbidity removal ratio interacted by PAM dosage and pH value. (right) Contour map of the turbidity removal ratio interacted by PAM dosage and $\mathrm{pH}$ value.

When the $\mathrm{pH}$ value was 12 , the turbidity removal ratio of the prepared flotation wastewater was improved with the increase in $\mathrm{CaCl}_{2}$ dosage, and the curved surface was inclined overall, which could be deduced by the very significant impact of $\mathrm{CaCl}_{2}$ dosage on the turbidity removal ratio. When $\mathrm{CaCl}_{2}$ dosage was $520-600 \mathrm{mg} / \mathrm{L}$ and PAM dosage was $20-25 \mathrm{mg} / \mathrm{L}$, the turbidity removal ratio was the highest. When PAM dosage was a fixed value, the difference of turbidity removal ratio with the change of $\mathrm{CaCl}_{2}$ dosage was more than $15 \%$. When $\mathrm{CaCl}_{2}$ dosage was constant, the difference of turbidity removal ratio with the change of PAM dosage was only about $5 \%$. Combined with the variation trend of the curved surface, it could be seen that the effect of $\mathrm{CaCl}_{2}$ dosage on the turbidity removal ratio was more significant than that of PAM dosage, which was consistent with the results of quadratic response surface model.

When PAM dosage was $30 \mathrm{mg} / \mathrm{L}$, the turbidity removal ratio was significantly improved with the increase in $\mathrm{CaCl}_{2}$ dosage, but the turbidity removal ratio was firstly raised then decreased with the $\mathrm{pH}$ value increased from 11 to 13 , and the curved surface was inclined overall. When the $\mathrm{CaCl}_{2}$ dosage was $520-600 \mathrm{mg} / \mathrm{L}$ and the $\mathrm{pH}$ value was 12 , the turbidity removal ratio was at the maximum. When the $\mathrm{CaCl}_{2}$ dosage was a fixed 
value, the difference of turbidity removal ratio with the change of $\mathrm{pH}$ value was about $3 \%$. Combined with the variation trend of the curved surface, it could be explained that $\mathrm{pH}$ value had a significant effect on the turbidity removal ratio, which was consistent with the results of variance analysis of the quadratic response surface model.

When $\mathrm{CaCl}_{2}$ dosage was $400 \mathrm{mg} / \mathrm{L}$ and PAM dosage was constant, the turbidity removal ratio was firstly raised then decreased with the $\mathrm{pH}$ value increased from 11 to 13 . The response surface and contour map of the turbidity removal ratio interacted by PAM dosage and $\mathrm{pH}$ value were saddle contours, which indicated that the interaction of PAM dosage and $\mathrm{pH}$ value was significant.

\subsection{Verification of Values Predicted by Quadratic Regression Response Model}

It could be observed from the response surfaces and contour maps that there was a maximum value of the turbidity removal ratio. The maximum turbidity removal ratio was selected by Design-Expert 8.0.6 software, then the optimal conditions of the quadratic response surface model could be predicted as follows: a $\mathrm{CaCl}_{2}$ dosage of $594.66 \mathrm{mg} / \mathrm{L}$, a PAM dosage of $21.10 \mathrm{mg} / \mathrm{L}$ and a $\mathrm{pH}$ value of 11.61 . The optimal conditions predicted by the quadratic response surface model were verified with three group parallel experiments in order to reduce the influence of experimental error. The experimental results are shown in Table 5.

Table 5. Verification of values predicted by the quadratic response surface model.

\begin{tabular}{ccccc}
\hline $\mathbf{C a C l}_{\mathbf{2}}$ Dosage $(\mathbf{m g} / \mathrm{L})$ & PAM Dosage $(\mathbf{m g} / \mathbf{L})$ & pH Value & Turbidity (NTU) & Turbidity Removal Ratio (\%) \\
\hline 595 & 21 & 11.58 & 0.23 & 99.98 \\
595 & 21 & 11.63 & 0.31 & 99.98 \\
595 & 21 & 11.59 & 0.18 & 99.99 \\
\hline
\end{tabular}

The results in Table 5 explain that the theoretical prediction was in good agreement with the experimental results, which indicates that the optimum experimental conditions obtained with the quadratic response surface model were credible and accurate.

\section{Conclusions}

$\mathrm{CaCl}_{2}$ was a more effective coagulant to remove SS from the prepared tungsten flotation wastewater than other coagulants commonly used in practical engineering such as PAC, PFS, $\mathrm{KAl}\left(\mathrm{SO}_{4}\right)_{2}$ and lime. When $595 \mathrm{mg} / \mathrm{L} \mathrm{CaCl}_{2}$ was combined with $21 \mathrm{mg} / \mathrm{L}$ $\mathrm{PAM}$ at $\mathrm{pH} 12$, the turbidity removal ratio could reach $99.98 \%$, and the residual turbidity of the supernatant was $0.23 \mathrm{NTU}$. The effluent could fully meet the requirements for reuse of industrial, urban miscellaneous and scenic environment water consumption (turbidity < $5 \mathrm{NTU}$ ). When $\mathrm{CaCl}_{2}$ dosage was $400 \mathrm{mg} / \mathrm{L}$, the turbidity removal ratio was about $92 \%$. The residual SS of the supernatant was about $222 \mathrm{mg} / \mathrm{L}$ (calculated according to Figure 3), which could meet the requirement for reuse of mineral processing water (SS $<300 \mathrm{mg} / \mathrm{L}$ ). Easy to dissolve and operate, $\mathrm{CaCl}_{2}$ could be widely used for $\mathrm{SS}$ removal from mineral flotation wastewater.

CCD designed through Design-Expert 8.0.6 software was employed to optimize and analyze the main influencing factors of the experimental process in order to reduce dosage and treatment cost. The quadratic equation model as $\mathrm{Y}=91.52+8.68 \mathrm{~A}+1.11 \mathrm{~B}-1.02 \mathrm{C}$ $-1.7 A B+0.86 A C+0.06 B C-1.56 A^{2}+2.09 B^{2}-1.89 C^{2}$ could predict the relationship between the independent variables and the response variable (turbidity removal ratio). The optimal conditions predicted by the quadratic equation model were verified with three group parallel experiments, and the predicted values were in good agreement with the experimental results, which indicated that the optimum experimental conditions obtained with the quadratic response surface model were credible and accurate. The quadratic equation model could provide strong support for the parameter optimization in the actual mineral flotation wastewater treatment process. 
Author Contributions: Conceptualization, L.Z. and X.J.; methodology, L.Z. and X.S.; software, X.S. and S.W.; validation, X.J. and S.W.; formal analysis, L.Z., X.S. and S.W.; investigation, X.J., X.S. and S.W.; resources, L.Z.; data curation, L.Z. and X.S.; writing-original draft preparation, L.Z., X.S. and R.Y.; writing-review and editing, L.Z. and S.W.; visualization, X.J., X.S. and S.W.; supervision, L.Z.; project administration, L.Z. and X.J.; funding acquisition, L.Z. All authors have read and agreed to the published version of the manuscript.

Funding: This work was supported by the National Key R\&D Program of China (NO. 2018YFC0406403-1).

Data Availability Statement: The data presented in this study are available on request from the corresponding author. The data are not publicly available due to the research process of this project.

Conflicts of Interest: The authors declare no conflict of interest.

\section{References}

1. Zhang, L.P.; Wu, S.N.; Song, X.J.; Cheng, X.N.; Zhang, X.; Jiao, X.F. Study on treatment of difficult settling wastewater from tungsten mineral processing. J. Min. Sci. Technol. 2020, 5, 687-695.

2. Kang, J.; Chen, C.; Sun, W.; Tang, H.; Yin, Z.; Liu, R.; Hu, Y.; Nguyen, A.V. A significant improvement of scheelite recovery using recycled flotation wastewater treated by hydrometallurgical waste acid. J. Clean. Prod. 2017, 151, 419-426. [CrossRef]

3. Liu, S.P.; Zhang, X.W.; Wei, F. Recovery of dissolved metals from beneficiation wastewater by electrochemical oxidation. Int. J. Electrochem. 2016, 11, 7173-7181. [CrossRef]

4. Gao, Y.; Gao, Z.; Sun, W.; Hu, Y. Selective flotation of scheelite from calcite: A novel reagent scheme. Int. J. Miner. Process. 2016, 154, 10-15. [CrossRef]

5. Wang, J.; Bai, J.; Yin, W.; Liang, X. Flotation separation of scheelite from calcite using carboxyl methyl cellulose as depressant. Miner. Eng. 2018, 127, 329-333. [CrossRef]

6. Feng, Z.; He, F.; Qiu, T. Research status and prospects of mineral processing wastewater treatment and cyclic utilization technology. Met. Mine 2016, 7, 71-77.

7. Kyzas, G.Z.; Matis, K.A. Flotation in water and wastewater treatment. Processes 2018, 6, 116-131. [CrossRef]

8. Tian, C.; Deng, M.; Wang, H.; Lin, C. Cyclic utilization of wastewater from scheelite dressing. Hydrometall. China 2015, 34, 253-255.

9. Liu, Y.; Yang, X.; Liu, F.; Yang, X.; Wang, F. Study on coagulation settlement test of mineral processing wastewater from a tungsten-molybdenum mine. In Proceedings of the IOP Conference Series: Earth and Environmental Science, Shanghai, China, 16-18 September 2019.

10. Dong, Y.H.; Chen, D.X.; Zhou, Y.C.; Hu, B.; Xiao, J. Application of combined flocculants on the reutilization of copper oxide ore dressing wastewater. Multipurp. Util. Miner. Resour. 2017, 1, 85-88.

11. Yang, W.; Cao, H.; Zhang, K.; Li, M.Y.; Li, J.H. Study on the effect of reusing wastewater of a Copper-Zinc mine in Xinjiang on flotation index. Nonferrous Met. Eng. 2019, 9, 69-75.

12. Li, H.S.; Liu, D.W.; Song, K.W. Impact of mineral processing wastewater on flotation process. Min. Metall. 2012, $21,94-96$.

13. Feng, Z.B.; Qiu, T.S.; Chen, J.G. Application and development on treating mineral processing wastewater by coagulation. Nonferrous Met. Sci. Eng. 2016, 7, 86-92.

14. Jiang, S.H.; Li, D.Q.; Zhou, C.B.; Zhang, L.M. Capabilities of stochastic response surface method and response surface method in reliability analysis. Struct. Eng. Mech. 2014, 49, 111-128. [CrossRef]

15. Xie, Y.; Chen, L.; Liu, R. Oxidation of AOX and organic compounds in pharmaceutical wastewater in RSM-optimized-Fenton system. Chemosphere 2016, 155, 217-224. [CrossRef] [PubMed]

16. Yang, Y.; Li, Y.; Zhang, Y.M.; Liang, D.W. Applying hybrid coagulants and polyacrylamide flocculants in the treatment of high-phosphorus hematite flotation wastewater (HHFW): Optimization through response surface methodology. Sep. Purif. Technol. 2010, 76, 72-78. [CrossRef]

17. Dawood, A.S.; Li, Y. Response surface methodology (RSM) for wastewater flocculation by a novel ( $\left.\mathrm{AlCl}_{3}-\mathrm{PAM}\right)$ hybrid polymer. In Proceedings of the Spring International Conference on Material Sciences and Technology, Xi'an, China, 27-30 May 2012; pp. 529-537.

18. Gao, Y.; Gao, Z.; Sun, W.; Yin, Z.; Wang, J.; Hu, Y. Adsorption of a novel reagent scheme on scheelite and calcite causing an effective flotation separation. J. Colloid Interface Sci. 2017, 512, 39-46. [CrossRef] [PubMed]

19. Zhu, H.; Qin, W.; Chen, C.; Liu, R. Interactions between sodium oleate and polyoxyethylene ether and the application in the low-temperature flotation of scheelite at 283K. J. Surfactants Deterg. 2016, 19, 1289-1295. [CrossRef]

20. Shao, P.; Qiu, Q.; Chen, H.J.; Zhu, J.Y.; Sun, P.L. Physicochemical stability of curcumin emulsions stabilized by Ulva fasciata polysaccharide under different metallic ions. Int. J. Biol. Macromol. 2017, 105, 154-162. [CrossRef] [PubMed]

21. Lin, Q.Q.; Liang, R.; Zhong, F.; Ye, A.Q.; Harjinde, S. Interactions between octenyl succinic anhydride modified starches and calcium in oil-in-water emulsions. Food Hydrocoll. 2018, 77, 30-39. [CrossRef] 
22. Wu, Y.Y.; Zhou, S.Q.; Qin, F.H.; Ye, X.Y.; Zheng, K. Modeling physical and oxidative removal properties of Fenton process for treatment of landfill leachate using response surface methodology (RSM). J. Hazard. Mater. 2010, 180, 456-465. [CrossRef] [PubMed]

23. Mason, R.L.; Gunst, R.F.; Hess, J.L. Statistical Design and Analysis of Experiments, Eighth Applications to Engineering and Science, 2nd ed.; Willey Press: New York, NY, USA, 2003; pp. 25-50. ISBN 978-04-7137-216-5. 